Pak. j. sci. ind. res. Ser. A: phys. sci. 2020 63A(3) 139-146

\title{
Dibutyl Phthalate an Emerging Contaminant in Water-Based Paints
}

\author{
Ajoke Fehintola Idayat Apanpa-Qasim ${ }^{\text {ab* }}$ \\ a Department of Chemistry, University of Ibadan, Ibadan-Nigeria \\ ${ }^{\mathrm{b}}$ CSIR-National Environmental Engineering and Research Institute, Nagpur, India \\ (received July 22, 2018; revised October 19, 2019; accepted November 14, 2019)
}

\begin{abstract}
Seven different manufacturers of paints were purchased from two major cities in southwest Nigeria. At least one sample from the same manufacturer and colour, was identified and analyzed for dibutyl phthalate (DBP). GC/MS method was developed for the identification and quantification of dibutyl phthalate in water-based paints after solvent extraction. The highest level of DBP found was 47,100 ppb (unregistered manufacturer), followed by 45,100 and 19,400 in a white, pink and cream coloured paint, respectively, while the lowest concentration was $721 \mathrm{ppb}$ in a cream coloured paints, unregistered manufacturer. The PCA results were in good accordance with the findings of the correlation coefficient. DBP is used by all manufacturers for flexibility and better spreadability. It is a cheap alternative and readily available. It's an emerging contaminant newly reported in paints and its toxicological effects should not be underestimated, since there is no regulation in place.
\end{abstract}

Keywords: emerging contaminant, dibutyl phthalate, environmental toxicology, gas chromatographymass spectrometry, multivariate statistical analysis

\section{Introduction}

Many articles have reported the presence of emerging compounds in consumer products such as phthalates, in the human and aquatic environments and wastewaters. Emerging pollutants are new chemicals without regulatory status and which impact on environment and human health are poorly understood (Lioy et al., 2015; USEPA, 2012).

Phthalates are produced in excess of million pounds per year (USEPA, 2012; EPA, 2006). Phthalates are used in several industrial and consumer products, basically as plasticizers (on Earth and NASEM, 2017; Lioy et al., 2015). They are released into the environment from different sources such as industrial releases, the disposal of productions, processing and industrial wastes, municipal wastes, sewage sludge and release from commodities containing phthalates Braun et al. (2013). The exact phthalate or combination of phthalates utilized in a specific product's formulation relies upon the properties the phthalates impart as well as their cost. Many phthalates can doubtlessly result in excessive exposure, both exclusively and together with other phthalates (Wang et al., 2019; Lioy et al., 2015; USEPA, 2012; Swan, 2008). They can frequently substitute for

*Author for correspondence; E-mail: ajoketola@gmail.com each other in products. U.S. Environmental Protection Agency's (EPA's) cutting-edge management plan considered the toxicity of phthalates, their occurrence in the environment and their considerable use and human exposure on Earth and (NASEM, 2017; CDC, 2005). Eight phthalates were considered: dibutyl phthalate (DBP), di-isobutyl phthalate (DIBP), butyl benzyl phthalate (BBP), di-n-pentyl phthalate (DnPP), di (2ethylhexyl) phthalate (DEHP), di- $n$-octyl phthalate (DnOP), di-isononyl phthalate (DINP), and di-isodecyl phthalate (DIDP), USEPA (2012). These phthalates shows adverse effects to aquatic organisms in ecotoxicity studies Oehlmann et al. (2009). Toxic effects were observed at environmentally relevant exposures at the low concentration that is, $\mathrm{ng} / \mathrm{L}$ to $\mu \mathrm{g} / \mathrm{L}$ range Oehlmann et al. (2009). Phthalates exposures can occur from releases that result from the production, processing or industrial use as well as contamination to air, water, food and dust resulting from the use or disposal of commodities containing phthalates (Wang et al., 2019; Lioy et al., 2015; Russo et al., 2015; Shaikh et al., 2012). Exposure sources of phthalates in the order of prevalence is food, cosmetics, consumer products (other than toys) and toys (Zota et al., 2016; Serrano et al., 2014; Hubinger, 2010; HSDB, 2009; Koo and Lee, 2004). 
Dibutyl phthalate (DBP) is one of the main sources of indoor semi-volatile organic compounds (SVOCs) and topmost persistent organic contaminants Wang et al. (2010). It is used as softener for better spreadability, flexibility, to retain scents and dispensability (Larsson et al., 2014; Chang et al., 2013; Green et al., 2005) as a solvent and fixative; a suspension agent; a lubricant for aerosol valves; an anti-foamer; a skin emollient, a plasticiser, fingernail elongators (extensions), in medical devices and textiles, as propellants, in food packaging, as dental materials, and in paper production (Wittassek et al., 2011; OSHA, 2009). However, in few illegal food industry applications, phthalates have been used as a low-fee alternative to update palm oil as a clouding agent added to juices, yogurt and drinks Chang et al. (2013). Dibutyl phthalate is one of the most popular phthalates used as clouding agent in drinks, which has been detected by the Taiwan Food and Drug Administration in 2011 (USEPA, 2012; HSDB, 2009).

Phthalates can be released from products and exposure may occur in humans through food, dust, air and direct use of personal care products (Janjua et al., 2008; Wittassek and Angerer, 2008; Wormuth et al., 2006). DBP is very stable and can enter to all primary environmental media. It causes the most lethally to terrestrial organisms, fish, and aquatic invertebrates Staples et al. (1997). Besides its role as endocrine disruptor, DBP has been shown to alter the expression of a number of genes, increased DNA damage in sperm, premature breast development, shortened pregnancy in women, and decrease in anogenital distance among male infants (Zare et al., 2018; Monneret, 2017; Swan et al., 2005; Duty et al., 2003; Colón et al. 2000). It exposure is of potential concern for children's health Craig et al. (2013). The National Toxicology Program concluded that high levels of di- $n$-butyl phthalate, may adversely affect human reproduction or development (Monneret, 2017; Sedha et al., 2015; Lin et al., 2011; Jahnke et al., 2005; NTP, 2003). They have also been measured in foods, milk and drinking water. The relative contribution from the various sources and routes of exposure to phthalates is unknown (Schecter et al., 2013; Fierens et al., 2012; Cao, 2010; Kolarik et al., 2008; Wormuth et al., 2006). Despite the enormous health effects, there remain no regulations on DBP in water-based paints manufactured and marketed in Nigeria. The objective of this work was to identify and access the levels of dibutyl phthalate, an emerging contaminants in water-based paints and their associated health effects.

\section{Materials and Methods}

Paint sampling. Paint samples of different colours and 14 manufacturers were purchased in popular paint markets in Ibadan and Lagos, Nigeria. A total of 174 paint samples were collected. These samples were stored in air-tight plastic containers and analysed at the Council of Scientific and Industrial Research-National Environmental Engineering Research Institute Laboratory, Nagpur - Maharashtra, India (Idayat Apanpa-Qasim and Adeyi, 2018).

Samples pre-treatment and analysis. Approximately $2.5 \mathrm{~mL}$ paint samples were carefully measured into 50 $\mathrm{mL}$ polypropylene radiation sterilized centrifuge tubes and $20 \mathrm{~mL}$ of ethyl acetate was then added ((Idayat Apanpa-Qasim and Adeyi, 2018). The centrifuge tubes were shaken and mixed on a cyclo mixer at 50 cycles (CM 101) for homogeneity of the samples. The tubes were centrifuged at $5000 \mathrm{rpm}$ at $20^{\circ} \mathrm{C}$ for $20 \mathrm{~min}$. The supernatant was filtered with PTFE micro-fibre syringe filter of $13 \mathrm{~mm}$ diameter and 0.22 micron pore size before analysis. The extracts were stored in $2 \mathrm{~mL}$ maxipense plastic vials analyzed using GC/MS. The internal standard (benzlyl benzoate) was added to all samples, blanks, and calibrators at known concentration.

Table 1. Instrument operating conditions

\begin{tabular}{lll}
\hline \hline Operating condition & GC-MS & $\begin{array}{l}\text { GC-MS } \\
\text { Monitoring ions } \\
(\mathrm{m} / \mathrm{z}) \text { used for } \\
\text { the identification }\end{array}$ \\
\hline Analytical column & $\begin{array}{l}\mathrm{DB} 5(30 \mathrm{~m} \times \\
0.25 \mathrm{~mm} \times 0.25 \mu \mathrm{m})\end{array}$ & $149,150,41$ \\
& Helium & \\
Carrier gas & $1.2 \mathrm{~mL} / \mathrm{min}$ & \\
Gas flow rate & $1 \mu \mathrm{L}$ & \\
Injection volume & $200^{\circ} \mathrm{C}$ & \\
Injection temperature & $280^{\circ} \mathrm{C}$ \\
Detector temperature & $180^{\circ} \mathrm{C}(0.5 \mathrm{~min})$ & \\
Column temperature & $-20^{\circ} \mathrm{C} / \mathrm{min}-280^{\circ} \mathrm{C}$ & \\
& $7 \mathrm{mins})$ & \\
Inlet source & & \\
temperature & $300^{\circ} \mathrm{C}$ & \\
Injection mode & $\mathrm{split}$ & \\
Solvent delay & $4.2 \mathrm{mins}$ & relative \\
Detector gain mode &
\end{tabular}


Instrument operating conditions is presented in Table 1. Recovery study was carried out and DBP recovery was of $86 \%$.

Statistical analysis. All the analyses were done in duplicate and the results were expressed in minimum and maximum values using MS-Excel. The data were also analyzed by using principal component analysis (PCA), cluster analysis (CA) and correlation coefficient using SPSS (Kumar et al., 2016; Trindade et al., 2015; Li et al., 2009).

\section{Results and Discussion}

Only 27 out of the 174 paint samples had DBP identified. The chromatogram and mass spectra of DBP are given in Fig. 1 and 2. This was confirmed based on the retention times and the molecular formula.

Concentrations of dibutyl phthalate in the different colours of paint samples by manufacturers based on ISO certification. Seven paint manufacturers with at least one sample each of the same colour were involved in this study. Two of the manufacturers were registered with Nigerian Industrial Standard (NIS) and International Organization for Standardization (ISO) and five unregistered manufacturers without NIS-ISO certification, producing different colours of water-based paints. The concentrations of the dibutyl phthalate in the paint samples with respect to manufacturers are presented in Table 2. Variation in dibutyl phthalate concentrations of paint samples with respect to colours produced by manufacturers are shown in Fig. 3 .

The range of levels of dibutyl phthalate in all the paint samples with respect to colour was 721 (cream)-47,100 ppb (white). The highest concentrations of dibutyl phthalate in all the 27 paint samples was $47,100 \mathrm{ppb}$ in a white coloured paint by manufacturer A, a registered manufacturer. This was followed by $45,100 \mathrm{ppb}$ in a pink coloured paint and 19,400 ppb in a cream coloured paint by the same manufacturer, while the lowest concentration was $721 \mathrm{ppb}$ in a cream coloured paints produced by manufacturer $\mathrm{D}$, an unregistered manufacturer. The order of dibutyl phthalate with respect to paint colours where present is:

DBP: pink $>$ white $>$ orange $>$ green $>$ blue $>$ cream $>$ yellow $>$ chocolate.

Correlation coefficient. The data obtained in this study was subjected to Pearson correlation coefficient and it was found out that the registration status (registered and unregistered status of the manufacturers) had a

Table 2. Concentrations ( $\mathrm{ppb}$ ) of dibutyl phthalate in paint samples with respect to manufacturers

\begin{tabular}{|c|c|c|c|c|c|}
\hline Colour grouping & Manufacturer codes & $\begin{array}{l}\text { NIS-ISO } \\
\text { registration }\end{array}$ & $\begin{array}{l}\text { Primary colours in } \\
\text { the paint samples }\end{array}$ & Sample 1 & Sample 2 \\
\hline NG 01 & A & RG & blue & 4900 & 5120 \\
\hline NG 03 & A & RG & yellow & 4880 & - \\
\hline NG 04 & A & RG & white & 47100 & - \\
\hline NG 05 & A & RG & pink & 45100 & - \\
\hline NG 06 & A & RG & cream & 19400 & - \\
\hline NG 07 & A & $\mathrm{RG}$ & green & 17600 & - \\
\hline NG 08 & $\mathrm{~B}$ & RG & white & 3400 & - \\
\hline NG 09 & $\mathrm{~B}$ & RG & blue & 8910 & - \\
\hline NG 10 & $\mathrm{C}$ & RG & cream & 2140 & - \\
\hline NG 11 & $\mathrm{D}$ & WRG & cream & 721 & - \\
\hline NG 12 & $\mathrm{E}$ & WRG & green & 5660 & - \\
\hline NG 14 & $\mathrm{E}$ & WRG & orange & 8190 & 7340 \\
\hline NG 15 & $\mathrm{E}$ & WRG & cream & 4080 & - \\
\hline NG 17 & $\mathrm{E}$ & WRG & green & 6120 & 5850 \\
\hline NG 18 & $\mathrm{E}$ & WRG & blue & 8860 & - \\
\hline NG 19 & $\mathrm{E}$ & WRG & cream & 3920 & - \\
\hline NG 20 & $\mathrm{E}$ & WRG & blue & 8050 & - \\
\hline NG 22 & $\mathrm{E}$ & WRG & white & 15500 & 15100 \\
\hline NG 23 & $\mathrm{~F}$ & WRG & chocolate & 1470 & - \\
\hline NG 24 & $\mathrm{~F}$ & WRG & blue & 3220 & - \\
\hline NG 25 & $\mathrm{~F}$ & WRG & green & 1550 & - \\
\hline NG 27 & G & WRG & cream & 2610 & 4190 \\
\hline
\end{tabular}

where RG means registered, WRG means without registration. 
positive correlation with manufacturers and dibutyl phthalate versus colour (Table 3 ). This signifies that the toxicity of dibutyl phthalate should not be underestimated in its usage by manufacturers of paints of different colours.

Principal components analysis (PCA). Two principal components were extracted using the PCA with rotated

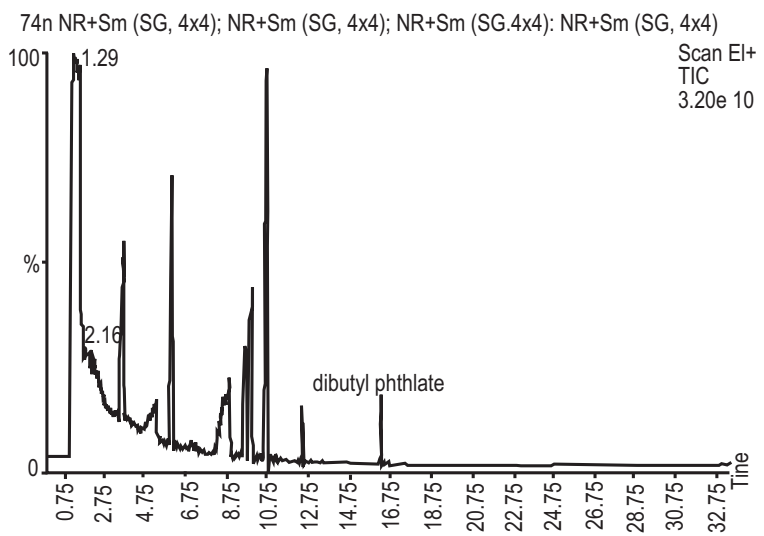

Fig. 1. Total ion chromatogram of dibutyl phthalate using GC-MS analysis.

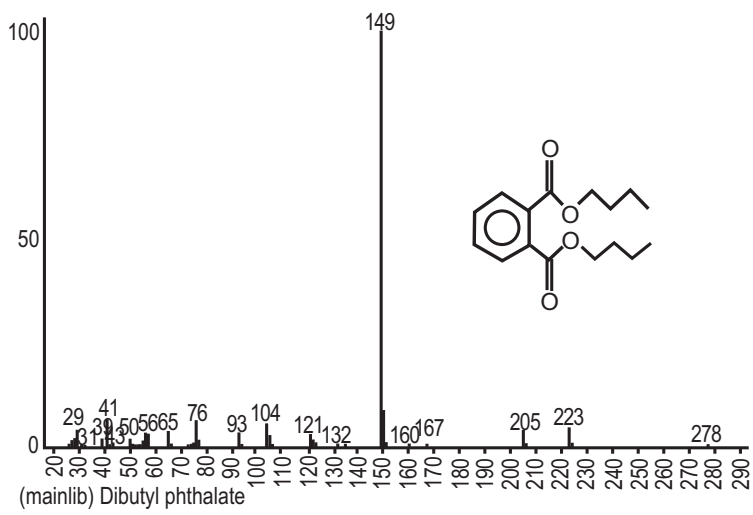

Fig. 2. Mass spectrums of dibutyl phthalate obtained after GC-MS analysis.

Table 3. Correlation coefficient of dibutyl phthalate in the paint samples

\begin{tabular}{lllll}
\hline \hline & $\begin{array}{l}\text { Manu- } \\
\text { facturers }\end{array}$ & $\begin{array}{l}\text { Dibutyl } \\
\text { phthalate }\end{array}$ & Colours & $\begin{array}{l}\text { Registration } \\
\text { status }\end{array}$ \\
\hline Manufacturers & 1 & $-0.492 * *$ & -0.186 & $0.923 * *$ \\
Dibutyl phthalate & 1 & $0.429 *$ & $-0.479 *$ \\
colours & & 1 & -0.161 \\
Registration status & & & 1 \\
\hline \hline
\end{tabular}

Note: $^{* *}=$ significant at $0.01,{ }^{*}=$ significant at 0.05 . component matrixes. Corresponding components, variable loadings, and the variances are presented in Table 4.

Only PCs with eigenvalues greater than 1 were considered. PCA of the whole data set yielded 2 data set explaining $86.25 \%$ of the total variance. The first component was responsible for $60.40 \%$ variance and

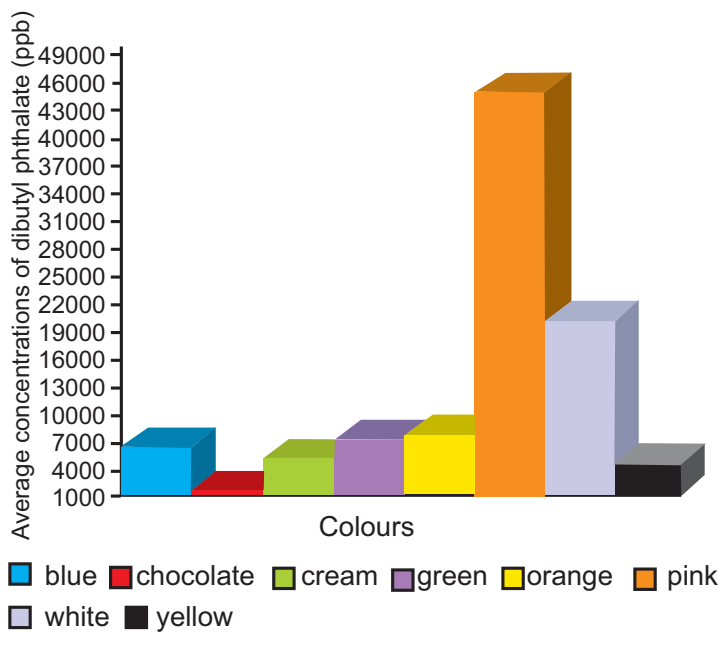

Fig. 3. Variation in concentrations of dibutyl phthalate in paints with respect to colours.

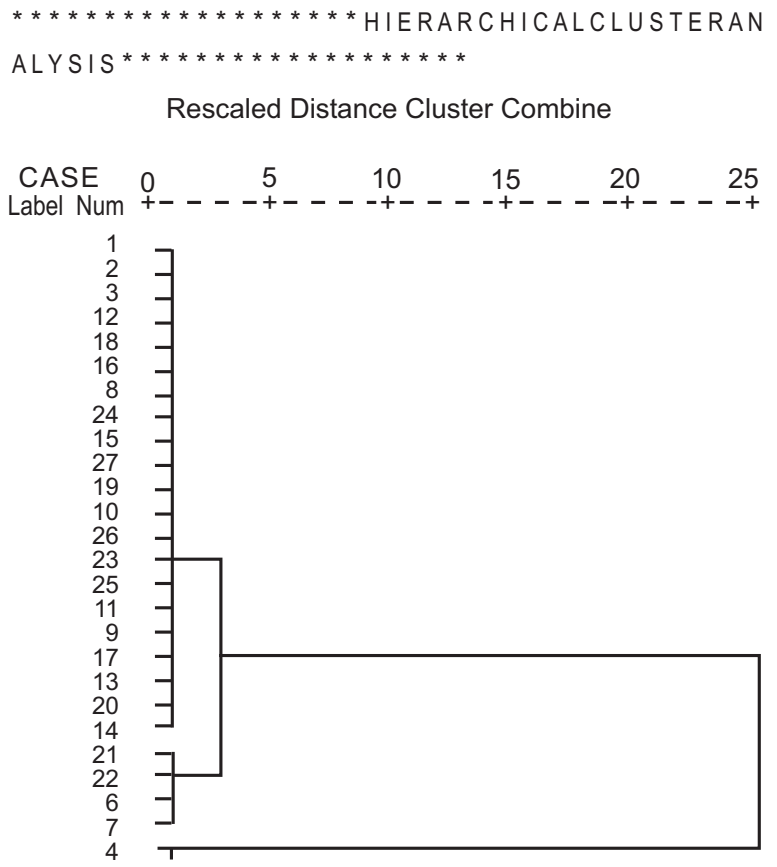

Fig. 4. Dendrogram showing the clusters of levels of dibutyl phthalates in paint samples. 
was best represented by the registration status of manufacturers. The second principal component includes all the manufacturers which accounts for $25.85 \%$ of the total variance.

The initial component matrix for dibutyl phthalates indicates that registration status and manufacturers are associated, showing high values in the first principal component (PC1) which explains $52.3 \%$ of the total variance and loads heavily on registration status (0.964), manufacturers (0.959). Registration status and manufacturers values are controlled by the producers of paints either registered companies or not. The second principal component (PC2) includes univocally colours and dibutyl phthalates, which accounts for $33.9 \%$ of the total variance. Common sources of colours in paints are majorly from pigments, and dibutyl phthalates influences the flexibility of paint produced. The analyzed results are in good accordance with the findings of the correlation coefficient.

Cluster analysis (CA). Cluster analysis (CA) was performed on the data using between-groups linkage method and squared Euclidean distance using the hierarchical clustering with SPSS software (Trindade et al., 2015; Li et al., 2009). Figure 4 shows the CA of dibutyl phthalate in the paint samples as a dendrogram. Two major clusters were obtained. Cluster 1: identified cases 1-3, 8-20, 23-27 and Cluster 2: cases 4 and 5. Cluster analysis revealed a division of the studied parameters into their similar class with respect to their normalized concentration levels.

\section{Conclusion}

This study predicts the possible human exposure to dibutyl phthalates in water-based paints, the levels were determined by GC/MS in 27 water-based paint samples. The low levels of DBP in water-based paints coincides with its physico-chemical characteristics (high volatility) that make DBP inappropriate for use in non-plastic products such as paints and probably as plasticizers in PVC found in packing materials. Chemicals such as DBP are used in a wide variety of consumer products (USEPA, 2012) they are suspected endocrine disrupters but their toxicity are poorly understood in paints. Combined exposure may occur through ingestion, inhalation and dermal exposure and their toxic as well as combined effects are poorly understood Larsson et al. (2014). Also, results from multivariate statistical analysis clearly show the use of DBP by all manufacturers for its flexibility and better spreadability in paint production in Nigeria despite its health effects. Hence, a need for stringent regulations to safe-guard public health from occupational exposure to these toxic and prohibited compounds is imperative.

\section{Acknowledgement}

Dr Apanpa-Qasim is grateful to The World Academy of Sciences for the Advancement of Science in

Table 4: Total variance and component matrixes extracted by PCA

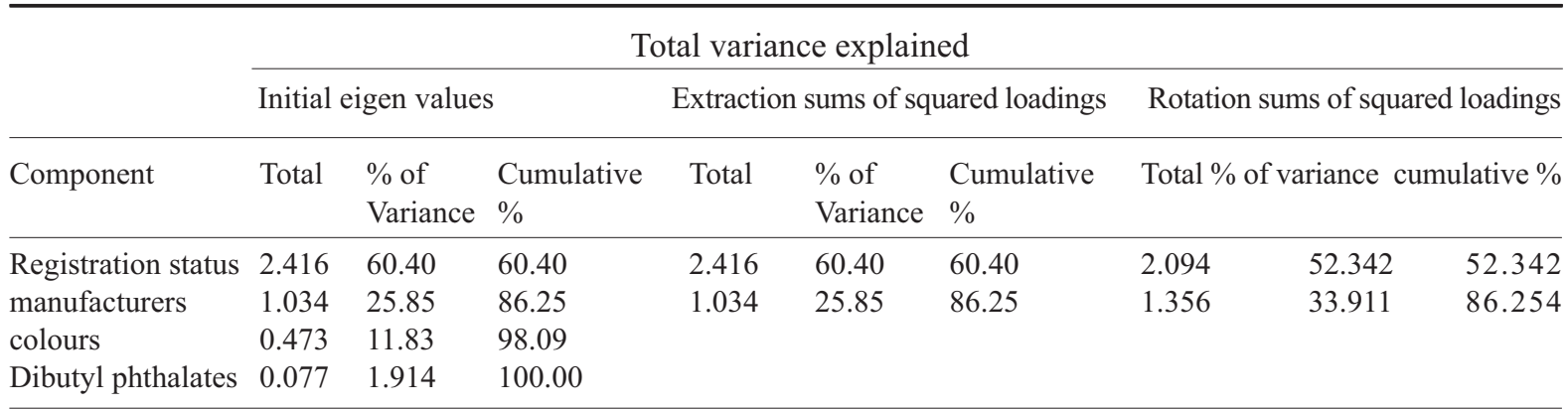

Extraction method: principal component analysis

(b) Component matrixes

\begin{tabular}{lllll}
\hline Component matrix & \multicolumn{2}{l}{ Rotated component matrix } & \multicolumn{2}{l}{ Compound } \\
\hline & PC1 & PC2 & PC1 & PC2 \\
Registration status & $\mathbf{0 . 9 0 1}$ & 0.362 & $\mathbf{0 . 9 6 4}$ & -0.118 \\
manufacturers & $\mathbf{0 . 9 1 0}$ & 0.336 & $\mathbf{0 . 9 5 9}$ & -0.145 \\
colours & -0.451 & $\mathbf{0 . 8 1 8}$ & -0.00005 & $\mathbf{0 . 9 3 4}$ \\
Dibutyl phthalates & $\mathbf{- 0 . 7 5 8}$ & 0.347 & -0.496 & $\mathbf{0 . 6 7 0}$ \\
\hline \hline
\end{tabular}


developing countries and the Council of Scientific and Industrial Research for funding part of this research (FR number: 3240275040). The director of National Environmental Engineering Research Institute, Nehru Marg, Nagpur, India is highly appreciated. Anonymous reviewers are greatly appreciated for their time and contributions in the review of this manuscript.

Conflict of Interest. The authors declare no conflict of interest.

\section{References}

Aly, H.A., Hassan, M.H., El-Beshbishy, H.A., Alahdal, A.M., Osman, A.M.M. 2016. Dibutyl phthalate induces oxidative stress and impairs spermatogenesis in adult rats. Toxicology and Industrial Health, 32: 1467-1477

Barrett, J.R. 2005. Chemical exposures: the ugly side of beauty products. Environmanal Health Perspectives, 113: A 24.

Braun, J.M., Sathyanarayana, S., Hauser, R. 2013. Phthalate exposure and children's health. Current Opinion in Pediatrics, 25: 247.

Cao, X.L. 2010. Phthalate esters in foods: sources, occurrence, and analytical methods. Comprehensive Reviews in Food Science and Food Safety, 9: 21-43.

CDC. 2005. Centers for Disease Control and Prevention. Third National Report on Human Exposure to Environmental Chemicals. Retrieved September 12 from http://www.cdc.gov/exposurereport/.

Chang, L.W., Hou, M.L., Tsai, T.H. 2013. Pharmacokinetics of dibutyl phthalate (DBP) in the rat determined by UPLC-MS/MS. International Journal of Molecular Sciences, 14: 836-849.

Colón, I., Caro, D., Bourdony, C.J., Rosario, O. 2000. Identification of phthalate esters in the serum of young Puerto Rican girls with premature breast development. Environmental Health Perspectives, 108: $895-900$.

Craig, Z.R., Hannon, P.R., Wang, W., Ziv-Gal, A., Flaws, J.A. 2013. Di-n-butyl phthalate disrupts the expression of genes involved in cell cycle and apoptotic pathways in mouse ovarian antral follicles. Biology of Reproduction, 88: 23-1.

Duty, S.M., Singh, N.P., Silva, M.J., Barr, D.B., Brock, J.W., Ryan, L., Herrick, R.F., Christiani, D.C., Hauser, R. 2003. The relationship between environmental exposures to phthalates and DNA damage in human sperm using the neutral comet assay. Environmental Health Perspectives, 111: 1164-1169.

Earth, D., National Academies of Sciences, Engineering, and Medicine (NASEM), 2017. Phthalates and Male Reproductive-Tract Development. In Application of Systematic Review Methods in an Overall Strategy for Evaluating Low-Dose Toxicity from Endocrine Active Chemicals. National Academies Press (US).

EPA. 2006. U.S. Environmental Protection Agency. Inventory Update Reporting (IUR): NonConfidential 2006 TSCA Inventory Update Rule (IUR) Records. Retrieved September 7, 2019 from http://cfpub.epa.gov/iursearch/index.cfm?s=chem.

Fierens, T., Servaes, K., Van Holderbeke, M., Geerts, L., De Henauw, S., Sioen, I., Vanermen, G. 2012. Analysis of phthalates in food products and packaging materials sold on the Belgian market. Food and Chemical Toxicology, 50: 2575-2583.

Genuis, S.J., Beesoon, S., Lobo, R.A., Birkholz, D. 2012. Human elimination of phthalate compounds: blood, urine and sweat (BUS) study. The Scientific World Journal, 2012.

Green, R., Hauser, R., Calafat, A.M., Weuve, J., Schettler, T., Ringer, S., Huttner, K., Hu, H. 2005. Use of di (2-ethylhexyl) phthalate-containing medical products and urinary levels of mono (2- ethylhexyl) phthalate in neonatal intensive care unit infants. Environmental Perspectives, 113: 1222-1225.

Hazardous Substance Data Bank. U.S. National Library of Medicine TOXNET System. Retrieved September 7, 2019 from http://toxnet.nlm.nih. gov/cgi-bin/sis/ htmlgen? HSDB .2009.

Hubinger, J.C. 2010. A survey of phthalate esters in consumer cosmetic products. Journal of Cosmetic Science, 61: 457-465.

Idayat Apanpa-Qasim, A.F., Adeyi, A.A. 2018. Oxygenated volatile organic compounds (antifreezing agents) in decorative water-based paints marketed in Nigeria. Journal of Health Pollution, 8: 180606.

Jahnke, G.D., Iannucci, A.R., Scialli, A.R., Shelby, M.D. 2005. Center for the evaluation of risks to human reproduction - the first five years. Birth Defects Research Part B: Developmental and Reproductive Toxicology, 74: 1-8.

Janjua, N.R., Frederiksen, H., Skakkebaek, N.E., Wulf, H.C., Andersson, A.M. 2008. Urinary excretion of phthalates and paraben after repeated whole-body 
topical application in humans. International Journal of Andrology, 31: 118-130.

Koo, H.J., Lee, B.M. 2004. Estimated exposure to phthalates in cosmetics and risk assessment. Journal of Toxicology and Environmental Health, Part A, 67: 1901-1914.

Kumar, V., Sharma, A., Chawla, A., Bhardwaj, R., Thukral, A.K., 2016. Water quality assessment of river Beas, India, using multivariate and remote sensing techniques. Environmental Monitoring and Assessment, 188: 137.

Larsson, K., Björklund, K.L., Palm, B., Wennberg, M., Kaj, L., Lindh, C.H., Jönsson, B.A., Berglund, M. 2014. Exposure determinants of phthalates, parabens, bisphenol A and triclosan in Swedish mothers and their children. Environment International, 73: 323-333.

Li, J., He, M., Han, W., Gu, Y. 2009. Analysis and assessment on heavy metal sources in the coastal soils developed from alluvial deposits using multivariate statistical methods. Journal of Hazardous Materials, 164: 976-981.

Lioy, P.J., Hauser, R., Gennings, C., Koch, H.M., Mirkes, P.E., Schwetz, B.A., Kortenkamp, A. 2015. Assessment of phthalates/phthalate alternatives in children's toys and childcare articles: Review of the report including conclusions and recommendation of the chronic hazard advisory panel of the consumer product safety commission. Journal of Exposure Science and Environmental Epidemiology, 25: 343.

Lin, S., Ku, H.Y., Su, P.H., Chen, J.W., Huang, P.C., Angerer, J., Wang, S.L. 2011. Phthalate exposure in pregnant women and their children in central Taiwan. Chemosphere, 82: 947-955.

Monneret, C. 2017. What is an endocrine disruptor. Comptes Rendus Biologies, 340: 403- 405.

National Toxicology Program. 2003. NTP-CERHR Monograph on the Potential Human Reproductive and Developmental Effects of Di-isononyl Phthalate (DINP). Ntp Cerhr Mon.

Occupational Safety and Health Guideline for Dibutyl Phthalate. Retrieved September 7, 2019 from http://www.osha.gov/SLTC/healthguidelines/dib utylphthalate/recognition.html. OSHA 2009.

Oehlmann, J., Schulte-Oehlmann, U., Kloas, W., Jagnytsch, O., Lutz, I., Kusk, K.O., Wollenberger, L., Santos, E.M., Paull, G.C., Van Look, K.J., Tyler, C.R. 2009. A critical analysis of the biological impacts of plasticizers on wildlife. Philosophical
Transactions of the Royal Society B: Biological Sciences, 364: 2047-2062.

Retrieved September 7, 2019 from https://www. epa.gov/sites/production/files/2015-09/documents/ phthalates_actionplan_revised_2012-03-14.pdf

Russo, M.V., Avino, P., Perugini, L., Notardonato, I. 2015. Extraction and GC-MS analysis of phthalate esters in food matrices: a review. RSC Advances, 5: 37023-37043.

Schecter, A., Lorber, M., Guo, Y., Wu, Q., Yun, S.H., Kannan, K., Hommel, M., Imran, N., Hynan, L.S., Cheng, D., Colacino, J.A. 2013. Phthalate concentrations and dietary exposure from food purchased in New York State. Environmental Health Perspectives, 121: 473-479.

Sedha, S., Kumar, S., Shukla, S. 2015. Role of oxidative stress in male reproductive dysfunctions with reference to phthalate compounds. Urology Journal, 12: 2304-2316.

Shaikh, H., Memon, N., Khan, H., Bhanger, M.I., Nizamani, S.M. 2012. Preparation and characterization of molecularly imprinted polymer for di (2-ethylhexyl) phthalate: Application to sample clean-up prior to gas chromatographic determination. Journal of Chromatography A, 1247: 125-133.

Serrano, S.E., Braun, J., Trasande, L., Dills, R., Sathyanarayana, S. 2014. Phthalates and diet: a review of the food monitoring and epidemiology data. Environmental Health, 13: 43.

Staples, C.A., Adams, W.J., Parkerton, T.F., Gorsuch, J.W., Biddinger, G.R., Reinert, K.H. 1997. Aquatic toxicity of eighteen phthalate esters. Environmental Toxicology and Chemistry: An International Journal, 16: 875-891.

Swan, S.H. 2008. Environmental phthalate exposure in relation to reproductive outcomes and other health endpoints in humans. Environmental Research, 108: $177-184$.

Swan, S.H., Main, K.M., Liu, F., Stewart, S.L., Kruse, R.L., Calafat, A.M., Mao, C.S., Redmon, J.B., Ternand, C.L., Sullivan, S., Teague, J.L. 2005. Decrease in anogenital distance among male infants with prenatal phthalate exposure. Environmental Health Perspectives, 113: 1056-1061.

Trindade, A.S., Dantas, A.F., Lima, D.C., Ferreira, S.L., Teixeira, L.S. 2015. Multivariate optimization of ultrasound-assisted extraction for determination of $\mathrm{Cu}, \mathrm{Fe}, \mathrm{Ni}$ and $\mathrm{Zn}$ in vegetable oils by highresolution continuum source atomic absorption 
spectrometry. Food Chemistry, 185: 145-150. United States Environmental Protection Agency (USEPA): Phthalates action plan summary.

Wang, C., Cheng, L., Zhang, L., Zuo, Y. 2019. Graphene oxide based molecularly imprinted polymers modified with $\beta$-cyclodextrin for selective extraction of di (2-ethylhexyl) phthalate in environmental waters. Journal of Separation Science, 42: 12481256.

Wittassek, M., Angerer, J. 2008. Phthalates: metabolism and exposure. International Journal of Andrology, 31: 131-138.

Wittassek, M., Koch, H.M., Angerer, J., Brüning, T. 2011. Assessing exposure to phthalates-the human biomonitoring approach. Molecular/Nutrition \&
Food Research, 55: 7- 31

Wormuth, M., Scheringer, M., Vollenweider, M., Hungerbühler, K., 2006. What are the sources of exposure to eight frequently used phthalic acid esters in Europeans?. Risk Analysis, 26: 803-824.

Yen, T.H., Lin-Tan, D.T., Lin, J.L. 2011. Food safety involving ingestion of foods and beverages prepared with phthalate-plasticizer-containing clouding agents. Journal of the Formosan Medical Association, 110: 671-684.

Zota, A.R., Phillips, C.A., Mitro, S.D. 2016. Recent fast food consumption and bisphenol $\mathrm{A}$ and phthalates exposures among the US population in NHANES, 2003-2010. Environmental Health Perspectives, 124: 1521-1528. 